\title{
7 Afghan Restaurants in Inter-Asian Worlds: Prestige, Information Pooling and Cross-Cultural Exchange in Long-Distance Trade
}

\section{Introduction}

The focus of this book thus far has been on the networks and nodes that are critical to the activities of long-distance Afghan traders and on the ability of these traders to navigate the complex Eurasian geopolitical contexts they inhabit. One of the overarching themes addressed in the previous chapters has been the significance of social institutions authored by the traders in maintaining and sustaining the networks through which they operate, and the nodes at which these coalesce. Social institutions of significance to the traders' activities have included diaspora organisations in the post-Soviet world and religious foundations in Turkey and Saudi Arabia. This chapter focuses on a specific type of social institution that Afghan traders use to anchor their networks and maintain their trading activities in the Eurasian and West Asian corridors of connectivity: the restaurant. To devote an entire chapter to establishments as apparently mundane as the restaurant in a book addressing the conduct of commerce at the interstices of Eurasian geopolitics might appear overly indulgent. Yet the 'Afghan restaurant' is a perennial feature of life across the settings Afghan traders work. Traders identifying as Afghan are not the only mobile people to visit such establishments on a regular basis; Afghan restaurants across the contexts explored in this book are frequented by diverse groups of mobile people, including West Africans, Gulf Arabs and Central Asians. Emphasising the interAsian significance of Afghan restaurants, the chapter extends the arguments advanced in Chapter 6 on the problems of assuming that Afghanistan occupies a peripheral position in Asia-wide dynamics. If the country's moneylenders play a critical role in the economic development of Eurasian trading nodes, then its restaurateurs and cooks are active agents in the cultural aspects of inter-Asian commercial settings.

An emerging body of literature in the anthropology of food and related disciplines has theorised the insights that restaurants offer into multiple areas 
of life. At one level, scholarship on restaurants focuses on the insights they furnish into the shifting and culturally diverse expressions taken by pleasure and leisure in the context of late capitalism. Anthropologists have examined, for instance, the management of tensions over leisure between restaurateurs, publics and Islamists in the Middle East. ${ }^{1}$ Other studies have explored the ways in which, in specific contexts, frequenting restaurants and teahouses enables engagements with 'diverse people and ideologies' and facilitates the development of a 'culture of hospitality and tolerance'. ${ }^{2}$ Most work on restaurants as sites of leisure in anthropology tends to dwell, however, on the insights that 'immigrant restaurants' in Euro-American cities reveal into the nature of 'late capitalism'. They focus on the role that subordinated immigrants - 'ethnic feeders' - have played in the development of urban life, the notion of 'ethnic' as a mode of reference that avoids the sensitivities of race and in the forms of 'cultural appropriation' and 'orientalism' in which such eateries and their clientele are implicated. ${ }^{3}$ More nuanced work emphasises the agency of 'ethnic restaurateurs' in the 'transaction of taste' and urges scholars to ask 'immigrant restaurateurs what they think' - a call to which I respond in this chapter, albeit in a very different type of setting from that of ethnic eateries in cities such as New York and London. ${ }^{4}$

At another level, anthropologists of food emphasise the varying ways in which the shared consumption of food - referred to as 'commensality' - is of critical significance to cultivating and sustaining social relationships and ties of trust. ${ }^{5}$ As we saw in Chapter 6 , the preparation and sharing of food is of deep significance to the ways in which traders establish and sustain relationships, both with one another and with state officials. Equally important, however, is recognition that everyday acts of food sharing are often imprinted with mistrust: traders often remark that having fed officials they will eventually end up 'being eaten' by them, underscoring the fraught and uncertain nature of their relations with people in positions of power and authority. ${ }^{6}$

Emphasising the importance of recognising the agency of cooks and restaurateurs as well as the relationship between food sharing and the experience of mistrust, this chapter focuses on intersections between restaurants and geopolitical processes. Afghan restaurants, it argues, are of critical importance to the transmission of shared sensibilities among traders identifying with the country and to complex forms of crosscultural exchange and interaction that take place in fraught geopolitical contexts. In an expanding literature on the insights that the study of

\footnotetext{
${ }^{1}$ Deeb and Harb 2014 and Salamandra 2004. $\quad{ }^{2}$ Suhail and Lutfi 2016.

${ }^{3}$ Narayan 1995. ${ }^{4}$ Ray 2016: 4. Lee 2009, Cho 2010.

5 See, for example, Kerner, Chou and Warmind 2015. ${ }^{6}$ Bloch 1999 and Fausto 2007.
} 
'sensory intercrossing and encounters' offers to theorising Asian interactions, many scholars have focused on historic and contemporary food practices culinary cultures. ${ }^{7}$ Jack Goody, for instance, argues that it is possible to distinguish the African and Eurasian civilisations on the basis of food cultures and processes of agricultural production. ${ }^{8}$ Building on Goody's geographically expansive scholarship, ${ }^{9}$ several anthropologists and historians have similarly explored processes of cultural interaction and mixing by way of an investigation of mobile food cultures and cuisines. ${ }^{10}$ At the same time, much scholarship has also recognised cuisine's critical role in the making of bounded forms of national and local identity. ${ }^{11}$ This chapter builds on these insights by exploring the geopolitical significance of restaurants and food to commerce and culture in inter-Asian settings.

In his work on Sufi lodges in central Bosnia, Henig underscores the important role played by food sharing not only in forging but also mediating multiple relationships in complex social and political environments. Henig argues that the Sufi lodges in which he has worked act as sites of everyday forms of 'gastro-diplomacy'. ${ }^{12}$ Building on Henig's work, in what follows I argue that restaurants are more than a mere backdrop to the making of social and commercial relationships. They are, rather, of vital significance to the durability of trading networks: traders collectively value restaurants as secure sites for the pooling of knowledge and information, and restaurateurs as well as cooks play an especially significant role in the overall cultural dynamics of networks. A great deal of work has emphasised the importance of a shared 'Muslim culture' to the forms of connectivity being established along the so-called 'New Silk Road'. 13 This chapter, by contrast, argues that a wider pool of resources is of importance for Afghan modes of navigating across fraught geopolitical contexts and the contributions they make and leave in the settings in which they live.

\section{Persian New Year in Yiwu}

One of my most memorable evenings while conducting fieldwork in Yiwu in 2016 fell on 20 March, the evening of Nowruz, Persian New Year.

${ }^{7}$ For an overview, see, Low 2019. $\quad{ }^{8}$ See, especially, Goody 1982 and Goody 1998.

${ }^{9}$ For an informative volume that critically assesses Goody's contribution to the field, see Klein and Murcott 2014.

${ }^{10}$ See, for example, Chapters 3 and 4 in Lambourn 2018 and Nabhan 2014. For an ethnographic study of the transregional aspects of food consumption in South Asia, see Osella and Osella 2007.

${ }^{11}$ See, for example, Raviv 2015 and Gvion 2014. ${ }^{12}$ Henig 2016.

${ }^{13}$ Simpfendorfer 2009. 
During fieldwork in Yiwu, I often went for a beer in one of the two ramshackle bars popular with foreign traders that were located in 'Maida' - the 'Middle Eastern' part of Yiwu discussed in Chapter 4. On previous evenings, I had met groups of traders from the Iranian cities of Gilan and the island of Kish, Afghans visiting Yiwu from Minsk with their Belarusian business partners, as well as Kenyans, Ugandans and Congolese merchant-migrants. This area was also the place in which I had witnessed the gatherings of Sikh and Hindu merchants discussed in Chapter 4. Spending time in Maida allowed me to get a broader perspective on life in the city than confining myself solely to Afghan spaces of commerce and sociality allowed.

On the evening of the Persian New Year, I met a trader in his late fifties from central Afghanistan. He informed me that he had come to Yiwu from Odessa in Ukraine to purchase the skateboards he sold on a wholesale basis in Odessa, a city in which he had lived for twenty years; it quickly turned out that we shared several friends in Odessa, including Dil Agha, whose business activities and friendship circles I discussed in Chapters 2 and 6. After a couple of toasts, we turned our attention to a group of young Iranian men and women also sitting in the street outside the bar. They were celebrating the New Year and dancing to Iranian pop music, telling us they were visitors to Yiwu from Tehran and Mashad.

A couple in their late fifties was sitting in a room that overlooked the street. After a while, the man and woman stood up to dance to the Persian music. After returning to the plastic table next to that around which I was sitting, the woman told us that she was originally from the western Pakistani city of Quetta; her husband was the son of an Iranian who had moved to Pakistan 'many years ago' in connection with the carpet trade. The couple, the woman's husband interjected, had for long been involved in the trade of used cars in Pakistan and had decided to visit China to see whether they could start importing goods - such as bags and textiles - to Pakistan. Over the course of the evening, it became apparent that the couple's trip to China had resulted in them realising that the costs of importing goods from China to Pakistan were too great for them.

Thus Farsi-speaking Afghans and Iranians, as well as a mixed UrduPersian-speaking couple, were all brought - momentarily - together through commerce in a city in maritime China. The setting in which this interaction arose was an impromptu and unplanned gathering in a Chinese beer shack frequented by a diverse and international clientele. The Iranian-Pakistani couple reminded me of Karachi's historic importance as an urban node for trade between South and West Asia. Connections between Iran and South Asia are widely documented by 
historians of the early modern world. ${ }^{14}$ Iran and British India also enjoyed a close and intimate relationship in the first decades of the twentieth century, especially in relation to the great cities of Karachi and Bombay. Commercial ties between Karachi and Iran remained important until the 1990s. Several Iranian traders told me in Yiwu, for example, that before they started to visit China in the late 1990s they had mostly purchased the commodities in which they dealt in Karachi's Saddar Bazaar. Markets in Saddar Bazaar that were important two decades ago - such as the Zainab souvenir and leather market that I visited in January 2000 along with friends from Chitral who excitedly told me of the Russian and Central Asian traders who shopped there - are only irregularly visited by international merchants today. Shifts such as these are also evident in the city's cuisine and the distribution of cafés. The rise of new commercial nodes (such as Yiwu) has inevitably resulted in the decline of prior nodes of transregional commerce and cultural exchange, such as Karachi. A Persian New Year spent in a beer shack in Yiwu ultimately illuminates much about the city's complex role as a site of inter-Asian connectivity.

\section{Come, Share My Table! Beyond Commensality}

Aside from time spent in shops and markets, it is in cafés and restaurants where I have spent a great deal of my time conducting fieldwork over the past decade or so. I have often been fortunate to be invited for meals in Afghan-owned restaurants by my friends and informants. I have also deployed popular eateries as places in which to strike up relationships with traders, including restaurateurs themselves, as well as their customers. In some contexts, this is a pleasurable aspect of fieldwork. My trips to Kabul are incomplete if they do not involve a trip to eateries in the old city (shahr-e kohna) in which rich and earthy dishes such as lamb and chickpea stew cooked slowly in metal teapots (chainaki) and slow-cooked cow feet and head (kaala pacha) are served to guests sitting cross-legged on wooden platforms and drinking pots of green tea left to brew for hours in great clay ovens.

Restaurants oriented towards an Afghan and Central Asian émigré clientele in Saudi Arabia were another unique setting in which to spend time. Diners in these Saudi restaurants were delighted to talk to me in Farsi and hear what news I had to report about their country - a country

14 An extensive body of literature exists on the history of connections between Iran and India and the forms of transregional 'Persianate' culture that such interactions played a role in forging. For an extensive discussion, see Eaton 2019, See also Cole 2002. On the need to go beyond Iran-India dynamics to understand the importance of the Persian language for Eurasia more generally, see Green 2019 and Kia 2020. 
that most of the younger men and boys in Jeddah have never visited. There was a marked contrast between the atmosphere in the restaurants and the shops I visited: in the latter space, shopkeepers reminded me of the likelihood that Saudi agents were closely observing me and that I should be mindful of what I said. Indeed, while chatting to one man in his shop, he asked me if I had spotted the 'agent' come in - a man who had asked about the cost of a piece of ready-made carpet before abruptly leaving without purchasing it, he told me, had visited the shop for no other reason than to observe my activities. By contrast, visiting inexpensive Central Asian Afghan eateries in Saudi Arabia afforded the opportunity to meet Afghans visiting Jeddah from the two cities in the kingdom that are home to substantial communities of Afghans but that Saudi law prohibits non-Muslims from visiting: Mecca and Madina. All too often, my fellow diners embarrassed me with unreturnable acts of hospitality and generosity: they would pay for my dishes without me knowing and leave, for example, therefore not even giving me a chance to remonstrate with them.

Elsewhere, however, sitting in restaurants regularly frequented by traders with the hope of meeting individuals and groups with whom to talk was a more trying experience. In Yiwu, traders are busy for much of the day in their offices; when not in their offices, they make frequent trips to the Futian wholesale market, the city's dry port and to their warehouses, located nearby. If I regularly visited trading offices in Yiwu, I was infrequently invited to spend time with them in the Futian market and not invited to accompany them to the port. My lack of access to this space presumably arose because of the secretive nature of their business activities, as well as from a concern among traders that they risked becoming the target of surveillance by the city authorities if they were seen spending time with me in official and highly monitored commercial spaces. During the course of a visit to Yiwu in September 2019, for example, I sat with two traders in an Afghan restaurant. The men remarked that it was harder to procure a Chinese business visa this year compared with previous years; this prompted them to ask me what the situation regarding visas was in relation to UK passports. I replied that being issued a research or ' $\mathrm{F}$ ' visa was more difficult, and that established professors had been denied a visa presumably as a result of their having made frequent trips to Xinjiang in the past. One of the traders responded, 'yes and with the situation in Hong Kong, you English will be under surveillance here and we will be too if they see us together'; the other man present remarked, however, that 'meeting in a restaurant no one pays any attention, but offices and houses would definitely raise attention'. 
Hence traders generally regard restaurants as a comparatively secure type of space in which to spend time and interact socially with a range of different types of people, including the visiting 'English'. So, when unable to find traders with whom to spend time, I would instead pass many a hot and humid afternoon in the city's restaurants and cafés. This would involve my waiting - often rather aimlessly - for a trader to enter the establishment with whom there was a possibility of striking up a conversation. Doing so was often very frustrating - on quiet days, few traders walked through the restaurant door; on busy days, they would enter restaurants with their international customers with the aim of talking business and agreeing upon deals rather than 'passing time' with a visiting researcher. Nevertheless, as I now explore, I did come to meet engaging and informative traders in restaurants and cafés and benefited from hours of intense discussion with them.

\section{Afghan Restaurants on the Global Stage}

In the months following the appointment of Hamid Karzai as Afghanistan's president in 2001, restaurants came to occupy a surprisingly visible place in the geopolitical imagination of the country. Karzai and his brothers ran a number of restaurants on the east and west coasts of the United States that quickly became the focus of global media attention. Karzai's background as a restaurateur was widely regarded as evidence that he was insufficiently experienced to run a country as complex as Afghanistan. Indeed, reflecting in 2011 on Karzai's presidency, Ashraf Ghani, a trained anthropologist, cast aspersions on Karzai's ability to manage an eatery let alone Afghanistan: 'Unlike his brothers, he couldn't even run a two room restaurant', Ghani remarked to a journalist. ${ }^{15}$

As I explore in the pages that follow, running a restaurant in an interAsian commercial node is considerably more complex than Ghani's remark about his political rival's businesses in the United States suggests. More importantly, the debate about the Karzai family's restaurant business reveals the extent to which in Afghanistan and among its diasporas restaurant ownership enacts claims of belonging to a prestigious elite rather than a marker of the 'subordinate class' of 'ethnic feeders'. The daughter of another former president of Afghanistan, Burhanuddin Rabbani, for example, has also opened a restaurant in an upmarket area of Dubai. During a visit to the restaurant in August 2018, she told me that her aim was to present a more 'authentic' version of the country's cuisine than was available to diners in the city's more 'popular' areas in which

${ }^{15}$ The Guardian, Monday, 23 March 2009. 
most if not all Afghan eateries are located. Indeed, for this woman and others in a similarly situated position, opening a restaurant is a clearly thought-out mode of advancing a competing interpretation of Afghanistan's polity and culture on the global stage. As a result, restaurants such as this one constitute an elite site of 'gastro-diplomacy': while they are not sanctioned by the nation state, they are located closer to the formal end of the spectrum of modes of doing diplomacy than the decidedly informal sites and activities explored in this book.

Before exploring the role of restaurants and eateries in inter-Asian trade, it is important to outline the diverse form taken by Afghan eateries in the varying contexts in which the networks are anchored. Afghan eateries are a feature of urban space in all the inter-Asian commercial nodes in which traders from Afghanistan work. The specific form such eateries takes varies from context to context, reflecting the wider cultural, commercial and political environments in which they are located. The variation that arises as a result of their location in time and space is visible in the aesthetics of restaurants, the food they serve and the profiles of their clientele.

In the formerly Soviet countries, most Afghan eateries fit the category of the 'workers' cafe'' (stolovaia) rather than that of 'the restaurant' with the latter's associations of pleasure, relaxation, competitive expenditure and the concomitant public display of social status. In almost all the markets in which Afghans work in formerly Soviet settings, small eateries that prepare a limited number of Afghan dishes are easy to find. Such eateries, usually nestled alongside those run by members of other international communities active in post-socialist markets (principally from Vietnam and the former Soviet Central Asian republics), cater to the daily food needs of Afghan traders. Men who have recently migrated to formerly Soviet countries from Afghanistan mostly run these eateries. Traders whose businesses are going through hard times often turn towards running a café as a way of making a living if they have little if any access to capital. Such eateries rarely employ men who would refer to themselves as 'cooks' in the professional sense of being experienced in preparing the types of Afghan dishes that tend to be served in restaurants. As we shall see later, in Afghanistan and elsewhere in Central Asia, professional cooks (ashpaz) receive apprentice-type instruction from a master (ustad) who is an expert in one or another type of culinary preparation. ${ }^{16}$ Restaurants in Afghanistan and in the diaspora employ

${ }^{16}$ In this sense, the forms of knowledge and discipline important in the training of master chefs (ustad) are similar to those involved in the transmission of different types of knowledge - from religious, to musical and cultural - in Central and West Asia. For an 
'masters' (ustad) trained in the arts of cooking different types of dishes, such as those made from rice (brinj), from dough and pasta (khamirbab) and from meat (gusht).

Cafés in the former Soviet Union have at most a couple of seats and chairs where hungry traders can sit and eat if they wish. More often, an Afghan eatery might not have such a seating area at all: an Afghan migrant seeking to earn a living through food preparation may instead cook basic dishes at home or pay a small fee to use the cooking facilities of a café owned by a Muslim Central Asian. He would then serve simple daily lunches (chasht) that traders eat mid-morning (work in Eurasia's wholesale markets tends to starts early, often around 5 a.m.). Most traders rarely take time out from their busy daily schedule to eat in the café; instead, they prefer cafés to deliver their meals to the shops, offices and warehouses in which they work. Afghan migrants labouring in such markets often deliver the traders' meals in large wheeled suitcases or trolleys, commodities imported to Eurasia from China by Afghan merchants. The ability of such cafés to serve clients across vast and labyrinthlike market complexes depends on those wheeling such suitcases having an intimate knowledge of the layout of commercial space, as well as the individual traders who work in them.

Having food delivered is important for reasons directly relating to the traders' businesses. On the one hand, it enables the speedy, efficient and inexpensive enactment of hospitality to friends and fellow traders on the occasions at which such folk drop by in one another's shops on businessrelated visits during the course of the day. For the most part, during such events traders would simply sit in one another's shops - often housed in shipping containers - and eat their meals out of the polystyrene containers in which they were delivered to them; passers-by known to them would be politely asked to join in the expectation that such formal invitations would be refused and recognised for what they were, ta'arof, ritualised displays of politeness of importance to cultures across the Persianate world. ${ }^{17}$ On the other hand, traders often offer a daily meal to their employees, regardless of whether they are from Afghanistan or are local; Afghanrun cafés regularly provide such meals and do so at minimum expense. Low-paid sellers and warehouse workers can eat on site, thereby reducing expenses in cost and time for their employer.

The ability to offer and benefit from the regular service of meals in this way is relatively novel for many of the traders. Before cafés were a regular

excellent ethnography of such relationships and modes of transmission in Yemen, see Marchand 2001.

17 On the enactment of ta'arof in Iran, see Beeman 1976. 
feature of the commercial landscapes of Eurasian markets, traders or their employees would cook their own lunch each day - or 'do a pot' (deg kardan). 'Doing a deg' mostly referred to cooking a soup (shorba) of meat, pulses and vegetables in a pressure cooker; additional ingredients such as coriander (gashneez) or a mixture of ground black pepper (murch-e siah) brought by traders themselves from northern Afghanistan distinguished soups from one another in relation to the regional backgrounds of the trader-cooks. The meals served by Afghan eateries in post-Soviet Eurasia, however, more closely approximate standardised Afghan ideas of 'restaurant food' than dishes traditionally cooked by men at their places of work. Café lunches largely consist of Afghan rice cooked with raisins and offered with red kidney bean stew (qorma-e lobiya) and salad, as well as grilled kebabs served alongside portions of salad, bread and chipped potatoes.

In addition to running pragmatic yet inexpensive Afghan eateries, since around 2010 successful Afghan traders have also established restaurants in the major commercial nodes in which their networks operate in postSoviet Eurasia, especially Moscow and Odessa. Despite being a new type of commercial institution, these restaurants arise out of a longer history of Eurasian geopolitics. In the years following the collapse of the Soviet Union, Afghans operated canteens in the universities and polytechnics in which they and students from other Muslim countries in West Asia had studied during the Soviet period. Located within university campuses, entrepreneurs transformed sections of institutional canteens into restaurants that attracted international students and Muslims living and working in such cities, as well as locals who enjoy the taste of 'Middle Eastern' dishes. These restaurants serve dishes specifically aimed at an Afghan clientele, but the food on offer is also of a type and standard generally not available in the working cafés discussed earlier. Dishes on the menus of establishments located in universities include rice dishes cooked with meat (palaw) and steamed stuffed dumplings, including those stuffed with mincemeat (known in Afghanistan as mantu) and filled with the Afghan leek, or gandana (known in Afghanistan as ashak). Various meat stews, especially qorma-e gosht (usually combining meat, chickpeas and sometimes potatoes) and karai shinwari (a stir-fry-type dish made from lamb, tomato and chilli favoured in eastern Afghanistan), are often also listed on the menu. Muslims from Arab countries (especially Syria, Yemen and Egypt) and Turkey form the largest immigrant group in cities such as Moscow and Odessa - newer Afghan restaurants recognise this and cater for more broadly 'Middle Eastern' palates: they sometimes employ Turkish chefs in addition to or even at the exclusion of cooks from Afghanistan and give their restaurants Arabic names, such as 'Bait 
al-Mandi'. These restaurants advertise themselves as being halal and do not serve the pork dishes that are ubiquitous in these countries' eateries more generally; it is rare, however, for them to prohibit customers from consuming alcohol on their premises - in this way, such establishments not only ensure that they are regarded as venues fit for the Muslim community but also that they are popular with a broader clientele.

Among Afghan traders, such restaurants have become significant sites for the collective and public display of social achievement and pleasure. Afghan traders often choose such establishments as venues for important community events, such as the Persian New Year festival of Nowruz and speeches and poetry recitals organised by Afghan diaspora associations in order to mark various occasions, such as the martyrdom of major political personalities. It is also common for traders to take guests and family visiting them from Afghanistan to these restaurants, as they cater to the halal sensitivities of those coming from the home country; perhaps more importantly, they are material demonstrations of the success of Afghans in the cities in which they live.

Yet the public social lives of Afghan traders are not confined to such settings. Traders are, in fact, more likely to organise dinners involving women family members in locally run restaurants as opposed to those owned by Afghans. In establishments run by locals, arrangements are made to ensure that pork is not served; those who wish to can also have a stronger drink with their friends and fellow merchants in such venues. For most of the traders in formerly Soviet Eurasia, taking the step of not serving pork is sufficient to ensure the designation of a meal as 'halal'. An important concern that also dictated traders' decisions about where to engage in acts of public social life is that of family privacy. When dining out, most Afghan women in post-Soviet Eurasia wear 'modern' (modarn) rather than 'traditional' (sunnati) clothing. They may or may not cover their heads. Given that families are more likely to meet co-nationals in specifically Afghan restaurants, family privacy and reputation is regarded as being easier to maintain and protect in locally run leisure spaces than in those run by Afghans themselves. Indeed, while the décor of this type of restaurant - notably the inclusion of side-seating areas concealed with curtains from public view - may appear to be of importance to Afghan families, such concealed spaces are generally used by all-male groups of traders wishing to hold conversations in private about familial and business issues. They also allow some traders to enjoy a drink without being seen by other members of their community in the restaurant.

Afghan eateries are also a visible feature of life in the commercial nodes in which Afghans operate in West Asia, though they are different in nature from those in post-Soviet Eurasia. As I mentioned briefly in Chapter 3, in 
Saudi Arabia and the Gulf states more generally Afghan restaurants occupy a large and vibrant niche in the cooked food sector of these powerful economies with their substantial populations of foreign workers. In these countries, Afghan dishes and cooking are familiar to local populations. In some contexts, as I explore later, they have become localised, even constituting aspects of the 'national cuisine' of specific Gulf countries. In contrast to the ad hoc nature of Eurasia's Afghan cafés, Afghan activity in the restaurant sector in West Asia is a focus of major and sustained investment. Rather than being the preserve of traders whose businesses have seen better days, as is the case in the Eurasian corridor, it also involves the circulation of expert cooks who have been trained and gained experience in Afghanistan. As a result, restaurants run by Afghans in West Asia are closely connected to Afghanistan. Businessmen in Afghanistan seeking suitable and reliable projects in which to invest capital in the Arabian Peninsula often choose the restaurant sector; to do so, they must establish ties with Afghan restaurateurs who are longterm residents in cities such as Jeddah, Dubai and Qatar and have knowledge of the sector and its potential markets as well as downfalls.

The 2010s have also seen the development of large and often transnational chains of Afghan restaurants in West Asia. These allow restaurateurs to better adjust to the vicissitudes of business in one or other of the countries across which they operate: in the event of a decline in the activities of a restaurant in one country, they can focus their investments in another country in which they run businesses. The nature of ties between such restaurants and Afghanistan is not reducible to flows of money alone - the mobility of people is also of importance to this type of activity. While Saudi Arabia's Afghan population has historically been of sufficient size to ensure a steady provision of cooks for restaurants serving local variants of Afghan dishes, in other settings (especially Dubai and Sharjah), restaurateurs regularly arrange working visas that allow them to bring experienced staff from Afghanistan to the UAE, as well as managerial and waiting staff.

West Asia's Afghan restaurants differ from those in Eurasia not only in terms of their scale; in their design and ambiance, too, Afghan eateries in West Asia consciously seek to resemble traditional restaurants in Afghanistan. The attempts of the region's Afghan restaurants to build upon historic cultures of public eatery are visible not only in their decor but also in the opportunities they offer for particular postural cultures of eating. These restaurants usually comprise spaces in which diners can sit on chairs around tables, as well as large raised seating platforms at which meals are consumed sitting cross-legged on decorated plastic sheets laid out on the floor. Such a spatial arrangement is recognisably 'Afghan' to 
those visiting such institutions - it draws upon the model of the chaykhana (teahouse) that serves food to guests and offers a sleeping area for travellers. ${ }^{18}$ In all such establishments, a high desk that the restaurantowner or manager occupies by sitting cross-legged on a raised platform is also given a prominent place. All monetary transactions are managed through this focal point of the restaurant; owners also often install surveillance devices to ensure they can closely monitor the till and prevent theft by the manager and the restaurant waiting staff.

The clientele in such West Asian restaurants is diverse. In Dubai, many such restaurants are located in a part of the city - Deira - that is mostly visited by travellers from Asia and Africa who are involved in relatively small-scale forms of trade and commerce. Afghan restaurants in Deira have earned a reputation among travellers for the filling, adequate and affordable food they offer. Indeed, the general approach taken by owners of these restaurants is high turnover and large volume - in this sense, their mode of doing business is comparable to the commercial preferences of most Afghan traders working across Eurasia. Dishes that can be cooked and served in large quantities (most items on the menu are accompanied by a large portion of rice cooked according to a favoured Afghan method) are their stock in trade. Despite the diversity of the clientele, unlike the Middle Eastern-oriented prestige restaurants of formerly Soviet Eurasian countries, these institutions are distinctly Afghan. Besides having spaces in which diners can sit cross-legged on carpeted floors and eat communally from large dishes, the walls of such restaurants are almost without fail adorned with large pictures of historic sites in Afghanistan; the national flags of Afghanistan and the UAE inevitably stand prominently on the manager's counter. In terms of their names, too, such eateries vigorously assert their distinctively Afghan heritage: 'al-kebab al Afghani', 'Emerald Rice' (Zamarud Palaw) and 'Qasr-e Kabul' (Palace of Kabul) are among the most favoured names for such establishments.

Afghan merchants have also opened restaurants in China, especially in Yiwu but also in the southern city of Guangzhou, despite the relatively small numbers of Afghans permanently based in the country, especially when compared with the former Soviet Union and West Asia's Gulf states. The form taken by Afghan restaurants in China is comparable to those in West Asia: they reflect the requirements of Muslim international traders in China and the nature of the local restaurant market. The key issue facing many if not all Muslim traders who visit China to procure commodities or who are permanently based in the country in connection with the trading companies they operate is the availability of halal food.

${ }^{18}$ For a description of chaykhanas in Afghanistan, see Saberi 1997. 
Traders from Afghanistan who travelled to China for trade in the early 1990s often speak of the difficulties they faced in procuring halal food: 'We would return home having eaten nothing for three weeks', they often remark. In Yiwu, the traders told me, there was initially a single eatery owned by a Chinese Hui Muslim that catered for the needs of all foreign Muslims living and visiting the city. In later years, Uyghur migrants to the city opened street stalls selling Xinjiang dishes (notably rice cooked with meat and carrots, kebabs, and noodle dishes served with vegetables and lamb or beef). In light of the limited availability of halal food of a type that suited Muslim visitors to the city from South and West Asia, a trader from Pakistan who had married a Chinese woman established the first foreignowned halal eatery in Yiwu. Established in 1999, the café was initially located inside the hotel mentioned in Chapter 4 that housed the offices of traders from Pakistan and Afghanistan. The redevelopment of that part of the city by the Yiwu authorities in 2017 meant that the restaurant's location eventually moved closer to the Futian market complex. Other establishments that catered to the culinary preferences of traders from Arabic-speaking countries followed on the heels of this Pakistani restaurant. Several restaurants served Yemeni dishes, the breakfast, meat and rice dishes of which, particularly the famed breakfast of eggs and vegetables (shakshoukha) and the rice and steam-roasted chicken dish 'mandi', are especially popular in West Asia and beyond. From the later 2000s, a large number of restaurants were established that catered to foreign Muslims, with Afghans, Syrians and Turks all opening new establishments. These new restaurants provided more options for visiting Muslim traders and catered to Chinese business owners seeking to secure clients of a Muslim background over dishes of food that were suitable for locals and foreign Muslim traders. This wave of restaurants also acted as a source of employment for capital-scant sojourners arriving in the city from Muslim Asia, especially against the backdrop of the wars in Syria, Yemen and Afghanistan. ${ }^{19}$ The rise of foreign-run restaurants, however, outpaced the number of foreigners visiting the city: by 2015, e-commerce had resulted in a significant decline of foreign visitors and the closure of several international restaurants, including those owned by Afghans, prompting restaurateurs to remark that this sector of the city's economy was in crisis (buhran).

In this context, restaurateurs from Afghanistan competed fiercely with one another and needed to explore new ways of keeping their restaurants financially viable. As we shall see, besides earning profits through food, restaurants are also important settings in which traders establish contact

${ }^{19}$ Anderson 2020. 
with merchants visiting the city from across the world. Nevertheless, most businesses of this type are unable to afford to maintain a side-activity such as a restaurant if they are economically unviable. In 2016, one of Yiwu's most popular eateries among Afghan traders based in the city was owned by an Afghan Turkmen trader with commercial experience in the Gulf, Turkey and Turkmenistan. The eatery's chef - a man in his mid-twenties from the northern town of Andkhuy - was known among traders in the city for cooking the most authentic version of the classic Afghan rice dishes (palaw) in Yiwu; its unassuming and distinctly Afghan floorseating area also encouraged traders to spend long afternoons drinking Afghan-style green tea flavoured with cardamom (chai-ye sabz) while chatting among themselves and the restaurant's owner. However, the owner ultimately decided to close the restaurant, telling me that while he had opened it 'to pass time' (sa'at teri) rather than to make a significant profit, it was now losing too much money to be sustainable. Afghan traders who owned offices in the part of the city in which the restaurant was located sought to persuade their friend to maintain the restaurant, arguing that it had many important spin-offs, most especially in terms of being a setting in which it was possible to meet and entertain potential customers for their businesses. The owner's priorities, however, had changed from the time at which he had opened the restaurant. After it had been closed, traders in this part of Yiwu had to eat their meals and entertain their guests in a Pakistani-owned establishment located close by.

More and more foreign Muslim restaurateurs recognised that if their business were to survive they would have to attract the custom not only of visiting foreign traders but also Chinese locals. In order to do so, many included halal versions of Chinese dishes on their menus, employing Chinese chefs - especially those identifying as Hui Muslims - in their kitchen staff. The owner of Yiwu's largest Afghan restaurant claims that his success resulted from incorporating Chinese dishes shortly after opening his two-floor eatery close to the city's central wholesale market. 'Yiwu is as quiet as it has ever been', he remarked to me one evening while we were sitting in his restaurant: 'We're still in business because most of our clientele is now Chinese - they like our Afghan dishes, but when eating out Chinese people like to order multiple dishes and our mixed ChineseAfghan menu allows them to do that. They are more important to us than foreigners and Afghans.'

Afghan restaurants and eateries are a visible feature in many of the most vibrant inter-Asian trading nodes today. The form they take is diverse, though there are similarities between those established in the former Soviet Union on the one hand and those that operate in China, Turkey 
and the Gulf on the other. As we shall now see, however, there is more to the restaurants owned and frequented by Afghan traders than the provision of food to mobile traders alone. If thought of as a specific type of social institution that is of significance to the dynamics of the trading networks as a whole, restaurants are helpfully considered as key sites in which traders negotiate relationships with people in positions of power and authority and engage in the navigation of geopolitical processes in the everyday.

\section{'Why Invest in a Restaurant If You Don't Know Powerful People': Materialising Influence, Information and Power}

One evening in July 2016, I was sitting on the upstairs floor of one of the most prominent Afghan restaurants in Zeytinburnu (the neighbourhood in Istanbul that is home to large Central Asian and Afghan communities that I explored in Chapter 3). Sitting by my side was the owner of the establishment - a merchant who had been involved in various forms of inter-Asian commerce over the past three decades, including the import to the UAE of used car parts from Tokyo, and the sale in Kabul of Chinese- and Turkish-made construction materials following the 2001 international intervention. The trader-restaurateur hailed from a region of central Afghanistan known to many in the country today as the ancestral home of Afghanistan's best-resourced trading families: the Dara-ye Turkmen (Turkmen Valley) in the province of Parwan. ${ }^{20}$ The merchant told me that he had been seeking to offset the weakened economic climate in Kabul and hostility towards Hazara traders from officials in the UAE by exploring business opportunities in Istanbul - the city to which he had also relocated his immediate family members, having rented a property and procured residency permits. Besides learning about this man's personal trajectory, the evening spent in the restaurant offered vivid insights into the role that such social institutions play as material embodiments of a merchant's influence. Shortly after I sat down with the owner, he moved to another table at which three Turkish customers sat; shortly after doing so, he beckoned me to join the men. Rather than hesitating to join the men - as I often do, for fear of interrupting their meeting - I accepted the invitation and joined the group. The restaurateur arranged a meal for the Turkish guests and myself, and talked to them in the Turkish that he had learned in Istanbul since moving to the city some six months previously. The meeting was relatively brief: after finishing their food, the

${ }^{20}$ The Hazara population of the valley identify themselves as being Sunni rather than Shi'i Muslims. 
Turkish guests departed and the trader-restaurateur bid them farewell. He then joined me and apologised that our conversation had been broken up by his guests, before explaining that the men were important figures in the local community: they owned a medical centre, were active in the local municipality and were well-known badmash (criminals; thugs) in Zeytinburnu. It was, he said, important to establish relationships (taluqat) with such individuals: owning a business in Zeytinburnu was impossible without the support and protection of such local figures.

Afghans with experience of life in Zeytinburnu and other settings in Turkey often tell me that the real purpose (hadaf) of the many Afghan restaurants is not to make a profit from the sale of food at all. Businesses such as these instead operate to provide the facilities for Afghans travelling to Western Europe to make payments to the 'people smugglers' (qachaqbar-e insan) involved in their transportation. Restaurants function, in short, as a 'front' for illicit forms of commercial activities. If, in Istanbul, Afghan restaurants are said to be the conduits of flows of money associated with informal forms of cross-border mobility, then they perform comparable roles in other settings in which Afghans live and work. In the UAE, for example, restaurants, alongside other businesses with a high daily cash turnover, such as car parks, are widely said by traders to be used by powerful figures in Afghanistan to 'clean' ( $p a k$ kardan) 'black money' (pul-e siah) either received illegally (in the form of bribes and kickbacks for contracts) or earned by way of criminal activities (notably the trade in opium and gemstones). Indeed, the rate at which restaurants come and go as well as rapid changes of ownership of particular establishments suggests that - at least in some contexts - the importance of earning a reputation for the quality of food served is outweighed by the ability of restaurateurs to conduct parallel commercial activities.

It is, however, too simple to see such restaurants as one-dimensional 'fronts' for illegal business activities. At one level, in order to avoid attracting the interest of authorities, restaurants functioning as fronts for criminal activity are more likely to specialise in the sale of a generic food type (notably pizzas) rather than something distinctly Afghan. This is because many traders think that authorities in the settings in which they operate will assume that businesses operated by Afghans are criminal in one way or another. More importantly, restaurants serve as a visible and tangible material manifestation of the close connections of their owners to figures as well as institutions of power and authority in the settings in which they are located. Material manifestations of local influence are important for two key reasons. First, they signal a degree of protection conferred upon a business and the people associated with it; this in turn 
functions as a marker of security and stability to potential investors. Traders often remark to me that only individuals with close ties to influential people open restaurants - otherwise, my interlocutors comment, why would someone risk investing so much capital in a single venture? Second, successful restaurateurs are known to have access to authoritative people: this means that, for traders, they have access to and hold key forms of commercial and political information. ${ }^{21}$ Most notably, traders assume that restaurateurs have access to a steady flow of reliable and critical information about policy developments that are of importance to the commercial activities of individual traders and wider networks.

Most restaurateurs operate trading businesses themselves - the widespread perception that the owners of such businesses have close ties to persons of power and authority helps to attract customers and traders seeking reliable companies and well-connected individuals with whom to work. As a result, meetings and discussions among traders about the pressing commercial and policy-related issues of the day are often held in restaurants - far from merely facilitating meetings through the provision of food and space, restaurateurs, as I now explore, play a pivotal role in organising, directing and overseeing such discussions.

\section{'If You're Thinking of Going to Malaysia to Buy Olive Oil, You're Making a Big Error': Restaurants and the Pooling of Commercial Information}

On a hot evening in Yiwu in August 2018, I was sitting - as I did on most if not all evenings - in one of the city's Afghan restaurants. The restaurant one of the largest of Yiwu's foreign eateries - comprised two floors of table and chair seating and was popular among international and Chinese merchants alike. A staff of around ten Hui Muslim employees from the southern province of Yunnan served guests, received payment for orders and managed its day-to-day running. Two managers in the restaurant came from Afghanistan to Yiwu specifically to work for the restaurateur. One of the two men (Lamaray) had initially worked at a wholesale clothing shop in central Kabul owned by the restaurateur's brother - he was employed in China having proven to be a trustworthy and even-tempered employee in Afghanistan. The relationship between the restauranteur and his manager was close and extended into realms of life other than business: when Lamaray planned to get married in 2016, for example, the

21 On the importance of 'indigenous' networks and agents to the circulation of information in colonial India, see Bayly 1996. 
Yiwu-based restaurateur offered him a generous interest-free loan (qarz) that helped to pay for the cost of the wedding (around $\$ 15,000$ ), which took place in Lamaray's modest family home in eastern Kabul. ${ }^{22}$ The kitchen staff is made up of Chinese Hui Muslim cooks and an ashpaz (chef) from Afghanistan. The chef employed in the restaurant was from Samangan in northern Afghanistan; his travel to China from Afghanistan was arranged by the restauranteur solely so that he could cook the Afghan palaw for which northern Afghanistan is especially famed.

It is relatively easy to strike up conversations with fellow diners in Afghan cafés and restaurants in West Asia and Eurasia. By contrast, in Yiwu the organisation of space in restaurants often frustrated my attempts to speak to traders over a meal. In particular, tables tend to be located far from one another, communal seating and dining spaces are rare and waiting staff remove menus and plates from adjacent seats on large tables, meaning that people do not generally join other diners unless they have been invited to do so. ${ }^{23}$ I was delighted, then, when the restaurant I most regularly frequented opened a 'coffee shop'. In this coffee shop, clients could order smaller dishes, drinks and shisha at tables located more closely to one another than those in the neighbouring restaurant. Waiting staff monitored diners less vigorously than was the case in the restaurant proper. Many of my Afghan associates would spend their evenings sharing a table in this café, and it became an especially fruitful place in which to conduct fieldwork - I would meet with men I knew in the café but was also often introduced to other traders entering the establishment. It was a more open setting in which to sit and join in discussions and games of cards than was the case in the formal restaurant next door. That the seats were comfortable (at least in comparison with the plastic chairs on which traders used to sit outside the adjacent restaurant until the municipal authorities banned them from doing so) no doubt also encouraged traders to linger in the café for longer stretches of time than they had previously in the restaurant. Indeed, the owner of the restaurant told me that, by opening the coffee shop, he had sought to create a space in which traders could interact with one another: 'We needed somewhere to sit and pass time', he told me one evening. 'It is alright to sit on chairs outside the restaurant, but it is cold in winter and hot in summer, and the sound of passing vehicles often means it is impossible to hear what anybody has to say.'

One evening was particularly helpful in leading me to recognise that restaurants such as this functioned as institutions in which traders

\footnotetext{
22 I visited Lamaray's home in Kabul shortly after his wedding in October 2016.

23 On the complex status of cafes as sites of intrusive state surveillance, see Verkaaik 2002.
} 
collectively pool information about commerce and individual reputation. On that evening, I entered the café and walked up the steps to its upper floor. On doing so, I came across a group of men, five of whom I knew from my earlier visits to the city, including the restaurant owner, who spent most of his evenings with friends, visiting clients and fellow traders either in the café or in the adjacent restaurant. The men gathered there were all Farsi-speakers and largely from the same region of central Afghanistan; they mostly ran or worked in transport and trading offices in Yiwu and oversaw the export of commodities bound for Kabul's Mandawi market.

The Yiwu-based traders soon introduced me to two men whom I had not previously met: one lived in Hamburg and was visiting Yiwu to buy plastic food containers; the other lived in a city in the west of England - he had travelled to China to purchase items relating to the two takeaway pizza restaurants he owned in the United Kingdom. As was the case on most evenings, the Yiwu-based traders became increasingly engrossed in a card game. In a highly performed manner, they traded insults and accusations of cheating with one another, knowing that the losing team would be expected to buy a round of ice cream for all in attendance. On busy nights, such performances would be watched avidly by Afghan traders from around the world; in the carefully regulated context of Yiwu, the performances surrounding card games constituted the closest approximation of the forms of public leisure and entertainment that I have suggested are critical to the cultural lives of Afghan traders in the range of settings in which they work. As the card game continued, I chatted with the two guests from Europe, who also began to share details of their commercial projects and aspirations with one another. The pizzashop owner from England informed us that he had been successful in the pizza trade despite being issued with warnings from two international pizza giants over the names of his pizza shops (Domenico's and Pizza Hot) and the menus they offered to customers. He was now seeking to expand his commercial activities: he wanted to open some type of factory in northern Afghanistan - perhaps in the bakery sector - and he was also interested in importing olive oil to Afghanistan, where there was a growing market for the product. It was, he reported, with the latter aim in mind that he was to travel some days later to Malaysia.

After hearing of his newly made acquaintance's plans, the Hamburgbased trader - who told me he had been involved in various types of trade since he was a child - asked the UK trader if he would be upset if he shared with him some frank advice. Upon being given the go-ahead to speak his mind, the Hamburg trader went on to say that opening a business in Afghanistan would be a disaster even if his friend intended to do so with 
the support of his brother: whatever money you throw into Afghanistan, he said, the country's dry soil will simply eat it up. He told the UK-based pizza-shop owner that some years ago he had travelled from Hamburg to his home city of Herat to open a stationery business; within months, he had lost his money and his relationships with close family members had soured over accusations of fraud and mistrust. 'Whatever you do', he remarked candidly to the pizza-shop owner from the United Kingdom, 'do not risk your capital in Afghanistan.' The Hamburg trader then went on to say that his friend also risked losing significant capital and time if he travelled to Malaysia to buy olive oil - owning a catering business in Germany, he could guarantee that there was no olive oil available in Malaysia, a country in which his newly made associate would only find low-quality palm oil. If he was intending to go to Malaysia just to pass some time, then fine - if, however, he really was seeking to do business there, then he should change his plans immediately.

'Social institutions' - here, cafés and restaurants - are significant sites for the open sharing of information about commerce and the feasibility of particular types of trading activity. Establishing such institutions is about more than merely opening a successful eatery; it is also about knowing how to create the spaces and contexts in which merchants are willing and feel sufficiently secure to share sensitive information, insights and opinions with one another. In Yiwu and many other nodes across Eurasia, traders are generally of the opinion that 'everyone is an agent'. In such geopolitically fraught environments, the ability to create spaces of exchange and information-sharing is no simple task. As we have seen in Yiwu, a restaurateur-trader devoted considerable capital and thought into the creation of a space in which traders could sit together and discuss matters of importance to them. Yet restaurateurs must also convey to their clientele that they are well connected to government officials, albeit not in a manner that raises questions of privacy and security. Traders suspected of actively supplying information about the activities of Afghans to local officials, or, indeed, of playing a part in government departments, such as official dispute resolution organisations, are the source of much critical comment in Yiwu. Even in restaurants owned by well-connected traders, Afghans are regularly reminded of the precarious and transient nature of their presence in Yiwu: police visits to cafés and restaurants often involve spot checks on the visas, residency permits and hotel details of 'foreigners', which leads traders to collectively discuss their poor treatment by the city authorities. In this environment, the owner of the restaurant in Yiwu is not only credited by Afghans in the city for having chosen the perfect location for his business; as importantly, his ability to navigate the concerns of traders and state officials has also ensured the lasting role his restaurant plays as a social institution in the experiences of the 
city's Afghans, and, more broadly, as is now explored, in the circulation of information that facilitates their commercial activities worldwide.

\section{'Saudi Arabia's Security Forces Were Eating Two Meals of Palaw Per Day!' Gastro-Diplomacy}

Restaurants play a critical role in ensuring the durability of trading networks: they mediate the relationships that traders forge with one another and with local authorities and power-holders. They are also key contexts in which traders pool and share information about commercial opportunities, as well as make assessments concerning the capabilities and reputations of merchants active in trading networks. Eateries are also especially important sites in which traders seek, if not always successfully, to engage in as convivial a manner as possible with neighbourhood-and municipality-level officials. As a great deal of scholarship has demonstrated, cuisine is also an arena for the display, transmission and exchange of cultural skills and knowledge; this is also visible in the influence of Afghan trading networks on the societies in which they operate, as well as on their modes of interacting with the multiple cultural settings in which they are immersed. This aspect of the Afghan eatery's contribution to interAsian connectivity is illuminated in an especially clear way through a consideration of the signature dish of most such restaurants: palaw. A consideration of the circulation of palaw through networks, its consumption in commercial nodes, the eateries in which it is served, the chefs who cook it and the diners attracted by it highlights Afghanistan's significance for the cultural dynamics of inter-Asia's 'sites of interaction'. ${ }^{24}$

\section{The Making of an Inter-Asian Cuisine: Bukhari Rice in Feddah and Beyond}

Bukhari rice (ruz-al bukhari) is a popular dish across the Kingdom of Saudi Arabia. Steamed with oil, carrots, raisins and spices favoured in the Arabian Peninsula (cardamom, all-spice, coriander, cumin and cinnamon), the long-grain rice (mainly of the lower-cost Sela that is parboiled in its husk and imported to Saudi Arabia from India and Pakistan) is served on enormous platters and usually topped with a piece of grilled chicken (dhajaj al-faham). ${ }^{25}$ Bukhari rice is mostly consumed in cheap

24 Harper and Amrith 2012.

25 In the extensive literature on rice's history as a 'global commodity', comparatively little analysis exists on the crop's history in Central Asia. See, for example, Bray 2015. According to Nesbitt, Simpson and Swanberg, rice has been cultivated in Afghanistan since the first millennia CE and was likely introduced to Central Asia from India by way 
eateries dotted across the kingdom's cities and small towns. The managers and cooks in such restaurants in Saudi Arabia mostly hail from the province of Sar-e Pol in the north of the country. Most of the Sar-e Pol restaurateurs, chefs and workers in Saudi Arabia are Uzbek-speakers whose trajectories of mobility closely resemble those of the traders who are active in the West Asian corridor of connectivity that I mapped out in Chapter 3. They migrated in the early 1980s from Afghanistan to Saudi Arabia by way of Pakistan, where they often stayed for several years in the cities of Peshawar, Lahore and Karachi, either operating Afghan restaurants or working as carpet weavers.

Rather than simply learning how to cook what Saudis sometimes refer to as their national dish, the restauranteurs engaged with the activities of an earlier wave of migrants to the kingdom from Afghanistan and Central Asia. As explored in detail in Chapter 3, the holy cities of the Hejaz have long been connected to Central Asian emirates such as Bukhara, Andijon and Qoqand, not to mention the principalities in what is now Xinjiang to the east, by historic forms of mobility and circulation. In Saudi Arabia, these successive waves of pilgrims, traders and exiles established eateries serving Bukhari rice and bakeries selling Central Asian-style naan (referred to as tamis in Saudi Arabia). Later waves of migrants who left northern Afghanistan in the 1980s initially entered into employment in Saudi Arabia by cooking in these establishments; in later years, they financed and managed such restaurants.

Traders involved in expanding the influence of 'Bukhari' restaurants in Saudi Arabia displayed similar forms of navigational agency to those that we have seen enacted by traders in economic and political spheres of life. 'The decision to call palaw [the generic Central/South Asian term for steamed rice] ruz al-bukhari was a strategic one', remarked Abu Bakr to me one day in a nargileh (water pipe) café in Istanbul's Zeytinburnu neighbourhood. Aged forty, Abu Bakr is the descendant of a trading family that originates from the Central Asian khanate of Andijon but has, for much of the past century, maintained homes, businesses and residences in Saudi Arabia, Afghanistan, the UAE and now Turkey a country in which he sought to extend his family's historic involvement in the trade of dried fruits and nuts, spices and rice:

of Iran. Palaw has been known as an important dish in Central and West Asia since the thirteenth century CE and has such a central place in the region's food culture that it is regarded by some specialists as being a 'superfood', though historically it was more likely to have been made with barley than rice. See Nesbitt, Mark, Simpson and Svanberg 2010. See also Chapter 5 of Spengler III 2020. Spengler III, Robert 2020. 
They calculated that the Saudis (who are very religious) would be attracted by the name because of the respect with which they held the Emirate of Bukhara, but, more importantly, Imam al-Bukhari [a ninth-century religious scholar who compiled an authoritative selection of hadith or sayings of the Prophet Muhammad]. In the years that followed, those involved in the Bukhari business made great profits. The rice became so popular that some companies even secured contracts to feed the Saudi security forces three meals a day, two of them ruz-al bukhari!

Ruz al-Bukhari bares only a family resemblance to the manner in which rice is prepared with meat, carrots, onions, raisins and sesame oil in northern Afghanistan. This mattered little to Afghanistan's Central Asian émigré entrepreneurs: if Saudi publics, as well as those visiting the country for trade, pilgrimage and labour, consumed heaps of Bukhari rice in eateries run by Central Asian Afghan émigrés, diners from Afghanistan would take up their positions in more modest cafés serving distinctively northern Afghan dishes. That a distinction exists between Central Asian palaw and its Saudi Arabian expression is evident in the form taken by restaurants specialising in the dish in the country. There are important differences between the venues aimed at Saudis and international migrants and eateries serving the Central Asian version of ruz al-bukhari. The latter establishments are mostly tucked away in the child-thronged backstreets of neighbourhoods in which substantial communities of Central Asian émigrés live, such as the Bukhariyya Street in Jeddah. In this type of eatery, Afghans and Central Asian émigrés gather to eat what they describe as food from northern Afghanistan, often remarking that the 'original' version of their dishes is too 'heavy' and 'strong' ( qawi) for Saudis. Alongside dishes of palaw (mounds of rice cooked with plenty of oil, meat, carrots and raisins), plates full of skewered kebabs and vessels of steaming cow foot stew (pacha) feature on menus as well as on sofra or daastarkhans (cloths around which diners sit when eating).

As we saw in Chapter 3, Central Asian émigré merchants active in Saudi Arabia have established wide-ranging and intricate networks that connect different parts of the region to one another and to settings beyond. Bukhari rice has travelled along these networks and come to play an important aspect of the culinary culture of a wide range of interAsian commercial nodes.

Central Asian émigré restaurateurs also carried their dishes and restaurant businesses to other places in the Arabian Peninsula, often travelling on circuitous routes and engaging with people from other communities as they did so. As we saw earlier in this chapter, Afghan eateries flooded the UAE market in the 2000s - the cash for such business often came from Afghanistan, but the chefs were frequently from émigré 
families based in Saudi Arabia. I met Dilmurad - a man in his thirties from a Central Asian Andijoni family that migrated to Kunduz (northern Afghanistan) in the 1920 s - in Zeytinburnu, where he ran a small stall selling sheer yakh (hand-made ice cream) to Afghan migrants. Dilmurad told me that he had spent most of his life in Al-Asif Square, the apartment blocks inhabited by Farsi- and Uzbek-speaking refugees of Central Asian backgrounds in Karachi that I introduced in Chapter 3. In the mid-2000s, a Yemeni restaurant chain in Ras $\mathrm{Al}$ Khaimah recruited Dilmurad to cook Bukhari rice to serve alongside Yemeni 'mandi' (steamed meat), arranging his visa and transport to the UAE. Forms of palaw that have been modified to suit Arab tastes are also now returning in their new guise to South Asia. Returnee middle-class migrants from Saudi Arabia miss the 'Arab cuisine' with which they became familiar in Saudi Arabia: three of the 'Arabic' restaurants serving 'mandi' that I visited in Karachi in 2017 were run by Central Asian émigré Afghans who had returned to Pakistan after decades living in Saudi Arabia.

Since the early 1990s, Istanbul has been the preferred destination for such traders to move their businesses and families. Farid - the son of a Bukharan émigré family who was born in Sar-e Pol and is now aged in his early seventies - moved his family to Istanbul from Mecca in the mid1990s. His sons continued to live in Mecca (where they were born) and ran the family business until 2016, when the prospect of higher taxes on business and family based in the kingdom reluctantly persuaded him that the time had come to leave the holy city. In 2017, he opened a restaurant in Zeytinburnu with the aim of keeping his sons busy. The restaurant did not cater to Afghans (at least ten such restaurants have opened in this part of Istanbul) but to Turks. Diners could choose between white Turkishstyle rice and 'yellow' or 'Uzbeki' palaw: palaw-branded Bukhari rice would not sell well in Istanbul, he remarked, so he advertised it as 'yellow rice' instead. Bukharan émigrés have opened other restaurants in Zeytinburnu that have similarly sought to expand their clientele by catering to the range of tastes popular in this part of Istanbul. A different establishment, for instance, was opened by an Uzbek-speaking Afghan Central Asia émigré who lives in Sweden; it serves dishes that are very particular to northern Afghanistan - such as a pasta dish made of layered dough interspersed with mincemeat known as Ay Khanum - alongside Uyghur specialities that it was hoped would attract Zeytinburnu's growing Uyghur community. ${ }^{26}$

The signature dish of Saudi Arabia's Central Asian émigrés a product, as we have seen earlier, of commercial calculations and

${ }^{26}$ On Uyghur migration to Turkey, see Bonnenfant 2017. 
interactions between the cuisines of Central Asia and the Arabian Peninsula - is now also a feature of nodes of significance in newer geographies of Eurasian connectivity, notably Yiwu. There is fierce competition between Afghan restaurants serving variations of palaw in Yiwu; hiring competent and trained specialists in the art of cooking the dish is of critical importance to the fortunes of such eateries. Both of the restaurants serving what Afghans in Yiwu regard as being 'authentic' (asli) palaw employ ethnically Uzbek and Turkmen cooks from northern Afghanistan.

I came to know Rahimullah while conducting fieldwork in Yiwu in 2016. Aged in his late twenties, he hails from the northern Afghan town of Andkhuy that I visited in October 2017 and described in Chapter 6. Before coming to China, Rahimullah had cooked in a restaurant owned by his mother's brother (mama) in Kabul's shahr-e naw (new city). During his time in Yiwu, Afghans knew him for cooking the city's most authentic palaw. Yet Rahimullah had also learned from his maternal uncle living in Kabul how to make dishes favoured by diners in Saudi Arabia, notably dajaj al-fahm - the uncle ensured that a plentiful supply of the spice mixture required for this dish reached Rahimullah in Yiwu from Afghanistan. Customers at the restaurant in which Abdullah worked included traders from Africa and the Middle East, many of whom had become accustomed to ruz al-Bukhari during the decades in which they had travelled to Dubai and Jeddah to purchase Chinese commodities for re-export to Africa from Afghan and Yemini traders. Bukhari rice has followed such networks and travelled along with merchants from Central Asia to the Hijaz, east to China and south-west to West Africa.

Rahimullah eventually returned to Afghanistan after the restaurant in which he worked closed. Initially, he hoped to open a restaurant in the southern city of Kandahar, where, he told me, there were few restaurants serving turkmeni palaw: unlike other cities in Afghanistan - such as Herat - he calculated, Kandahris would take well to palaw-e turkmeni because they enjoyed eating meals in large quantities. Rahimullah was, however, unable to find a suitable investor for such a project in Kandahar and so opened, along with a partner, a restaurant serving palaw-e turkmeni in a largely residential part of Kabul not far from Shahr-e Naw. On the several occasions that I visited Rahimullah in the restaurant in the autumn of 2018, however, it was clear that the establishment was not doing as well as he had hoped; Rahimullah eventually closed the restaurant in Afghanistan and was employed as a palaw chef by an Afghan restaurateur living in Dubai. Meanwhile, Rahimullah's elder brother moved to China, 
where he was tasked exclusively with the role of palaw chef in a Pakistani restaurant in the city of Keqiao (China's 'textile city'). ${ }^{27}$

Afghanistan's Central Asian émigrés are skilled in feeding the diverse 'mobile societies' that circulate within and across inter-Asian networks and commercial nodes. Rather than simply nurturing the Central Asian émigré diaspora, they demonstrate navigational agency in their ability to provide a form of cuisine that is loved and cherished by people of diverse backgrounds. Another location in which Afghanistan's Central Asian émigrés have staked out their culinary presence over the past two decades is Manchester, especially the city's Wilmslow Road, which is located close to one of its universities. In Manchester, rather than acting as the 'ethnic feeders' of local middle classes, the primary market for the émigré restaurateurs are Middle Eastern students eager for a taste of home. Giving their establishments in this context distinctively Arabic (rather than Afghan or Central Asian) names (such as al-Taybah al-Bukhari and AlJazeera), Central Asian émigrés in Manchester attract Arab students and also compete with one another for the custom of Malay students. ${ }^{28}$ Malaysians experiment in culinary terms by trying the tastes of 'the Middle East', even if what they are consuming are adapted versions of Afghan dishes cooked by Afghan Central Asian émigrés; the thousand or so Saudi students in Manchester are delighted with the plentiful supply of their 'national dish' far away from home.

\section{Sesame Oil Rice and Kabul Restaurants: Authenticity and Ethnicity in Afghanistan}

The transactions of taste upon which this chapter has focused thus far have been shaped, mediated by and carried along Afghan networks operating in a wide range of inter-Asian nodes. Importantly, however, food's significance to inter-Asian cultural dynamics is also related to developments within Afghanistan. Shifts in the preparation of particular 'Afghan' dishes in inter-Asian commercial nodes circulate in Afghanistan, influencing not only food in the country but also the types of restaurants in which it is served and the forms of identities with which it is implicated. Central Asia's émigrés have for long played an important role in the culinary dynamics of Kabul and Afghanistan more generally. Dishes referred to as 'Afghan', I am often told, have their origins in societies 'across the river' in Central Asia rather than in the territories making up the country today; there is, indeed, a widespread awareness of the importance of historic connections to the development of the country's culinary heritage. Older

27 Cheuk $2015 \quad{ }^{28}$ Ibnu 2019. 
Kabulis remember street stalls that were owned by Central Asian émigrés who sold Bukhari-style mantu (stuffed pasta dumplings) and sambusa (baked mincemeat pies) in the pol-e takhta street of the old city (shahr-e kohna), for example.

Food viewed as being distinctly Central Asian continues to be regarded positively in the country today. Over the past ten years, there has been an explosion in the number of restaurants in Afghanistan that advertise themselves as serving forms of palaw associated with Afghanistan's Central Asian émigrés. ${ }^{29}$ In Kabul's central and modern Shahr-e Nau neighbourhood, for instance, there are clusters of eateries advertising the delicious dishes of 'Uzbeki' and 'Turkmen' palaw in which they specialise. A key selling point of such restaurants is that the meat served in the rice is brought daily to Kabul from the pastures of northern Afghanistan; the oil in which the meat and onions is fried before slow cooking commences is also advertised as a distinctly northern Afghan product, 'sesame oil' (rughan-e kunjit). Restaurateurs give such restaurants distinctly Turkic names associated with older and newer imperial projects: 'Osmani' (Ottoman) is a particularly favoured restaurant name among émigré communities in Kabul. Turkey's 'pivot to the East' is, indeed, manifested materially in this part of Kabul - 'the Ankara roundabout' (chahrahi ankara) is located at the intersection of a street with a multistorey shopping complex housing Turkish shops and a restaurant, and another on which shopkeepers from the Turkish city of Eskisehir sell stoves. Restaurants in this part of Kabul regularly serve dishes that Central Asian émigrés have perfected in West Asia, such as dajaj alfahm. They also attract middle-class Afghans, many of whom have spent time studying, working or trading in Istanbul, by preparing Turkish staples, such as doner kebabs and lentil soups.

In Henig's formulation, Afghanistan's Central Asian émigrés demonstrate their skill as flexible actors in the field of 'gastro-diplomacy', at the same time as earning a name and collective repute for their ability to prepare authentic Central Asian, Arab and Turkish dishes; in doing so, they also demonstrate their understanding of versatility in multiple cultures and languages. As we saw in Chapter 3, their ability to navigate an expansive world region similar in scope to what Ahmed has referred to as the 'Balkans-to-Bengal' complex, even in the context of this world being divided geopolitically, is based on decades of work and travel in the West Asian corridor and beyond. They have adapted palaw to multiple markets and cultures yet sought to maintain their reputation as the carriers of the

29 Contrast with Helen Saberi's description of the limited variety of public eateries in Kabul in the 1970s and 1980s; see Saberi 1991. 
'authentic' dish. Their simultaneous association with cosmopolitan and regionally authentic cultures underscores the degree to which cultural exchange, openness and closedness, interaction and boundary maintenance, and flexibility and the need to authenticate constitute two sides of the same coin. ${ }^{30}$

If cuisine, cooks and restaurants are agents of inter-Asian circulation and exchange, then they are simultaneously implicated in the production and instantiation of bounded ethnolinguistic identities, sensibilities and distinctions. The restaurants and forms of cooking explored earlier are characterised by their flexibility and the imprint of decades and more of inter-Asian mobility; the same community, however, has established other institutions that point to the cultivation of narrower forms of ethnic identity. ${ }^{31}$ Abdullah (the trader of Turkmen background whose attempts to locate a debtor I discussed in Chapter 6) took me to a restaurant in Mazar-e Sharif that proudly claimed it was the first 'Turkmen' eatery in the city. In addition to displaying items of traditional Turkmen clothing and serving the palaw and dough-based dishes that are common across northern Afghanistan, the small eatery, which is located not far from the city's shrine to Ali, marked its distinctively Turkmen identity by serving a dish that had hitherto only rarely if ever been available in Afghanistan's restaurants, and, indeed, was rarely prepared in the home: Ishleki. Ishlekisometimes referred to jokingly by informants as 'Turkmen pizza' - comprises minced meat and onions in a pastry crust; traditionally, the dish was slow-cooked in an earthenware container placed in the embers of the hearth of the Turkmen home. ${ }^{32}$ I had only eaten ishleki on one prior occasion, having been offered it by a police officer in Kunduz to whom members of the local Turkmen community had presented the delicacy as a 'gift'. The eatery in Mazar-e Sharif, a Turkmen trader in Yiwu had told me, was the first place in which ishleki had been available for sale in Afghanistan, despite the country's sizeable and historic Turkmen community and their renowned status as chefs. Abdullah told me that the owner of the restaurant - who was not present during our visit - had spent several years living and working in Istanbul: it was in Zeytinburnu where he had arrived at the idea of establishing an authentic Turkmen eatery in his home city of Mazar-e Sharif. Abdullah was not, however, entirely satisfied with the authenticity of the Turkmen dishes served at the

${ }^{30}$ See, for comparison, Osella and Caroline Osella 2007.

31 On the importance of food to ethnic identity in Central Asia, see Zanca 2007. On food's importance to Afghan diasporic identities, see Dossa 2014 and Monsutti 2010.

32 As with other dishes celebrated in Turkic communities in northern Afghanistan and Central Asia, the dish's origins lie in the historically mobile lifestyles of Turkmen pastoralists; see Perry 1996. 
restaurants: there were tomatoes in the meat filling - not something, he noted, that he remembered his Turkmen grandmother ever adding to the ishleki she had cooked at home during his youth. Circulations and exchanges of an inter-Asian scale and scope produce open and adaptive forms of identity, but they also play a role in identity formations that emphasise boundaries and fixed understandings of authenticity; Central Asian émigrés, as well as other trading networks studied in this book, are simultaneously involved in both sets of processes.

In his study of Armenian trading networks, Aslanian has argued that in addition to the circulation of commodities and credit, the movement of trained religious personnel was critical to 'the maintenance of the identity/ integrity of the network'; such figures, as a result, were regarded as 'jealously guarded possessions'. ${ }^{33}$ Individuals learned in the field of the Islamic sciences who circulate between inter-Asian nodes are also valued in the networks under study in this book. In addition to valuing the status of authoritative holders of religious knowledge, Afghans conversant in specific cultural genres, especially poetic and musical production, play a critical role in informing the ideological and cultural reproduction of trading networks. Acknowledged figures of religious and cultural authority, however, regularly combine the roles they play in processes of ideological reproduction with those of being active traders, merchants and investors. The imam (prayer leader) in one of Odessa's two Afghan mosques, for example, is a trader who is educated in the Islamic sciences. Similarly, a trader based in Yiwu who has committed the Qur'an to memory (a hafiz-e qur'an) presides over important religious events organised by Afghans in China. Many other traders are also skilled in the field of commerce and regarded as cultural experts - something they enact when using literary Persian in the context of being comperes at Afghan cultural events, for instance, or writing books on Afghan history and culture at the same time as over-seeing wholesale shops and trading companies. Indeed, when Afghan traders hire the services of religious specialists to carry out particularly important religious rituals (most especially in order to recite the Qur'an in its entirety during the month of Ramadan), they are pragmatic in terms of the choices they make about whom to spend hard-earned money on. Afghans in Yiwu, for example, agreed to bring a religious specialist from Mumbai to China to recite the Qur'an during Ramadan; an Afghan religious expert, I was told, would have been expensive in terms of finance and the time that traders in the city would have been expected to spend with a guest from their 'homeland'. It is not surprising that the role played by religious specialists in the reproduction of Afghan and Armenian trading

33 Aslanian 2014. 
networks differs in important ways: not only have secular forms of polity and government narrowed the scope for the role played by religious authority in the organisations of mobile societies but so too are there significant theological differences in the forms of globally influential Sunni Islam adhered to by most Afghan traders and the more specific forms of Christianity developed by the Armenian Apostolic Church.

I have suggested in this chapter that men such as Rahimullah who are trained in the art of cooking palaw can also be seen as 'jealously guarded' cultural specialists among Afghan long-distance trading networks. Rahimullah's case demonstrates that chefs who have specialised in the cooking of the relevant variant of this dish - including the Saudi Arabianinspired ruz al-bukhari - are widely sought after in the nodes in which Afghan trading networks coalesce. Chefs circulate far and wide between multiple nodes of Asian connectivity, moving back and forth between Jeddah, Yiwu, Dubai and Istanbul. Trader-restaurateurs also go to considerable lengths to bring chefs from regions of Afghanistan that are known as being cultural centres for knowledge about how to best prepare authentic dishes, especially palaw. In order to navigate Chinese visa regulations, for example, cooks are regularly included as partners in trading businesses; this course of action poses a considerable risk for trader-restaurateurs - the China business visas of all individuals registered as partners of a company depend on their being present in China in order to sign the document that confirms they are in an ongoing partnership or otherwise involved in the business. As a result, chefs hold a degree of power and influence over such companies - this is something that they can demonstrate in threats to return to Afghanistan (often made if their working pay and conditions do not meet their expectations) or seek work elsewhere. Traders are largely confident in their ability to maintain the significance of Islamic and cultural practices and knowledge to their collective activities, identities and expressions of familiarity without hiring the services of religious professionals. In the sphere of cuisine, however, the traders take specific steps to maintain authenticity - they also challenge establishments that threaten Afghanistan's reputation by serving 'copies' of the country's famed cuisine. Though chefs are certainly not the priests of Afghan networks, they do provide a window into the multiplicity of actors involved in the cultural reproduction of Afghan networks, as well as the multiple levels at which such reproduction occurs.

\section{Conclusion}

This chapter has identified four ways in which restaurants are important to long-distance inter-Asian trade in the first decades of the twenty-first 
century. First, restaurants address a significant and everyday need of mobile traders and those who work for them: they provide regular, affordable and reliable food for mobile actors who do not constitute a 'global elite' but often work on the basis of tight profit margins. Second, the ability to conduct the forms of trade discussed in this book requires that members of networks pool information about commercial dynamics as well as the individual and collective reputations of traders. Doing so in geopolitically divided and tense contexts in which 'everyone is an agent', however, is no simple task. In such contexts, tradersrestaurateurs play a critical role in cultivating spaces in which sensitive knowledge about commerce and reputation can be safely transmitted. Third, in the inter-Asian commercial nodes we have explored it is widely assumed that establishing and maintaining a restaurant requires political acumen and relationships with power-holders on the part of the restaurateur. Restaurants, in these contexts, are not only safe settings of knowledge transmission; they also materialise and symbolise power, influence, connectivity and authority at the collective and individual levels.

Finally, restaurants are important vehicles for the cultural interpenetration of Asian societies. As a result, they thus have long-lasting implications for traders and their networks, and also for the wider societies and cultures within and across which these operate. In this respect, restaurants differ from other 'neighbourhood institutions' explored and analysed in this book, such as diaspora organisations and religious foundations. If those institutions play a critical role in encouraging and - where necessary - enforcing hierarchical ties of loyalty between traders and the wider networks within which they work, restaurants also facilitate 'transactions in taste' within the societies in which they operate.

The inter-Asian circulations of various manifestations of Afghan cuisine explored in this chapter contribute to the book's more general argument about the need to rethink the conventional geographies through which Asian connectivity is addressed and explored. On the one hand, the significance of palaw and the restaurants that serve it to the culinary dynamics of some of Asia's greatest trade hubs - from Istanbul, Jeddah and Dubai in West Asia to Yiwu in China and Odessa and Moscow in the post-Soviet world - underscores the degree to which Afghanistan is not a peripheral feature of inter-Asian dynamics. In Chapter 6, I argued that Kabul is an important node in long-distance trading networks, especially in terms of the provision of capital. In this chapter, I have argued that Afghanistan's mobile societies are also culturally influential, especially in the arena of cuisine, and that such influence is clearly visible in multiple hubs of interAsian commerce. On the other hand, traders regard cuisine as having great significance for their collective activities and identities, as well as the 
manner in which they are perceived by people in the societies across which they work. And this underscores the ways in which inter-Asian traders deploy a multiplicity of cultural and ideological resources to navigate multiple geopolitical projects and the range of settings these often simultaneously shape and influence.

Because most of the Afghan traders whose activities are documented in this book are Muslim, it might be assumed that religion is inevitably the aspect of their identities that matters most to the cultural composition of their networks. However, the significance traders attach to cuisine and the social institutions, spaces and authoritative personnel connected to it shows how far the traders actively draw from a wide pool of cultural and ideological resources. As I have suggested in this and other chapters, there are two reasons why such resources are essential for understanding the durability of the networks. First, they ensure the cultural reproduction of their networks and the forms of familiarity between those making them up. Second, access to, awareness of and fluency in multiple cultural resources inform the ways in which the traders conceive of and exercise navigational agency in the complex geopolitical contexts across which they work. Cuisine plays an influential role in mediating the traders' individual and collective relationships with states, societies and officials in contexts as diverse and varied as the Gulf, Russia, China and Turkey. The forms of cuisine promoted by the traders transcend narrow understandings of their belonging to a 'national diaspora' - they illuminate, instead, the role played by traders in historically enduring interactions of multiple societies and cultures within the Eurasian arena. As palaw's shifting nomenclature illustrates, the historic role played by mobile societies in such processes of cultural exchange, interaction and interpenetration is something that the traders consciously emphasise and de-emphasise depending on the geopolitical dynamics of the particular setting in which they live and work. The story of palaw thus illuminates the interplay between the flexible and shifting identities of trading networks premised on familiarity with multiple cultural resources and those that are narrower and ethnically particular in shape and form. 